•研究报告・

\title{
用植物生活史性状预测种子扩散方式
}

\author{
郭志文 郑景明* \\ (北京林业大学林学院, 北京 100083)
}

\begin{abstract}
摘要: 种子扩散方式对植物物种分布、种群动态及群落组成都有重要影响, 但目前有关种子扩散方式的数据还很 欠缺。植物的生活史性状与种子扩散方式联系密切, 通过植物生活史性状预测种子的扩散方式是一种有效的研究 手段。本文基于我国 360 种植物的生长型、株高、种子质量和果实类型以及种子扩散方式的数据集，随机抽取288 个物种数据(80\%)作为训练样本, 采用神经网络、决策树、费舍尔线性判别和支持向量机算法, 分别建立种子扩散 方式的预测模型，将其余 72 个物种数据(20\%)用于模型检验。以 1,000 次随机抽样后的平均判别正确率作为模型预 测效果的评价指标。结果表明: 用生长型、株高、种子质量及果实类型作为主要预测变量, 构建的神经网络、决 策树、费希尔线性判别和支持向量机模型均能达到较好的预测效果, 准确率分别为 $78.90 \% 、 77.09 \% 、 77.81 \%$ 和 $78.14 \%$, 其中以神经网络模型的预测效果最好。进一步研究发现, 神经网络模型对动物扩散、无助力扩散和风扩 散的预测效果分别为 $81.32 \% 、 74.90 \%$ 和 $81.45 \%$ 。本研究为植物种子扩散方式预测提供了一种新的思路。
\end{abstract}

关键词: 扩散方式; 果实类型; 生长型; 株高; 种子质量; 预测模型

\section{Predicting modes of seed dispersal using plant life history traits}

Zhiwen Guo, Jingming Zheng*

College of Forestry, Beijing Forestry University, Beijing 100083

\begin{abstract}
Mode of seed dispersal is an important trait for understanding geographical distributions, population dynamics, and community composition of plant species. However, data of dispersal modes are scarce for Chinese plant species. Previous studies have shown that growth form, plant height, fruit type, and seed mass have strong correlations with seed dispersal modes, thus predictions using modelling could be an alternative to gain this information. We collected information on growth forms, plant height, fruit types, seed mass, and dispersal modes from 360 kinds of Chinese angiosperm plants, and built a neural network model (NNET), decision tree (TREE), Fisher linear discriminant model (LDA), and support vector machine model (SVM) to predict seed syndromes from these four traits. For each model, an $80 \%$ sample (288 species) was randomly drawn from dataset as the training sample, with remaining $20 \%$ of data was used as a test sample. Results showed that all four models achieved rather good predictions, and the average total correctness rate for the NNET, TREE, LDA, and SVM was 78.90\%, 77.09\%, 77.81\%, 78.14\%, respectively. The neural network model had the highest correctness rates for different dispersal modes, i.e., zoochory (81.32\%), autochory (74.90\%), and anemochory (81.45\%). This paper establishes the basis for the prediction of seed dispersal modes.
\end{abstract}

Key words: dispersal modes; fruit type; growth form; plant height; seed mass; prediction model

种子扩散是植物生活史的重要阶段, 营固着生 活的植物都要通过种子扩散来扩大种群和提高幼 苗成活率(Willson, 1993; Jordano et al, 2011)。种子扩 散的时空格局决定了植物群落的分布格局(Clark et al, 1998; 于顺利等, 2007; 姚蓓等, 2015)及地理分 布范围(Cain et al, 1998, 2000; Neubert \& Caswell, 2000; Hewitt \& Kellman, 2002; 郑景明等, 2004; Thuiller et al, 2008), 且与种子扩散方式关系密切, 
表1 5 个植物生活史性状的分类水平及划分方法

Table 1 The protocol of classification level in five life history traits of plant

\begin{tabular}{lll}
\hline 生活史性状 Life history trait & 分类水平 Class level & 参考文献 Reference \\
\hline 生长型 Growth form & 草本; 灌木; 藤本; 乔木 Herb; Shrub; Vine; Tree & Flora Reipublicae Popularis Sinicae, 1979 \\
株高 Plant height & $<0.5 \mathrm{~m} ; 0.5-2.0 \mathrm{~m} ; 2.0-5.0 \mathrm{~m}$; > 5.0 m & Westoby et al, 1990 \\
果实类型 Fruit type & 裂果; 闭果; 肉质果 Dehisce; Achene; Fruit & Flora Reipublicae Popularis Sinicae, 1979 \\
种子质量 Seed mass & $<0.1 \mathrm{mg} ; 0.1-100 \mathrm{mg} ;>100 \mathrm{mg}$ & Westoby et al, 1996 \\
扩散方式 Dispersal mode & 无助力扩散; 风扩散; 动物扩散 Autochory; Anemochory; Zoochory & Baskin \& Baskin, 1998, 2014 \\
\hline
\end{tabular}

但目前国内外的种子扩散方式数据还明显不足。建 立种子扩散方式预测模型能够获得大量的植物种 子扩散方式数据, 有助于今后开展相关生态学研究。

种子扩散方式与植物的生长型、株高、果实类 型和种子质量等生活史性状密切相关(Westoby et al, 1992; Thomson et al, 2010)。在以木本植物占优势(尤 其是乔木居多)的森林中, 动物扩散的比例通常较 高(李娟等, 2013)。种子大小与扩散方式也密切相关, 动物协助扩散的种子质量比风扩散和无助力扩散 的种子大(Westoby et al, 1990, 1996; Leishman \& Westoby, 1994; 张大勇, 2004), 扩散方式能够解释 种子质量变异的20-29\% (Leishman et al, 1995; Moles et al, 2005)。株高对于无助力扩散和风扩散种 子的扩散效率有显著影响, 高大植物更有利于无助 力扩散和风扩散种子形成有效的扩散距离(Thompson \& Rabinowitz, 1989; 于顺利等, 2007; Thomson et al, 2011; Li et al, 2012)。

以上研究表明通过植物生活史性状来预测种 子的扩散方式是可行的(Hughes et al, 1994; Thomson et al, 2010)。本文利用360种植物的生长型、株 高、果实类型和种子质量 4 个生活史性状以及扩散 方式数据(附录1), 在分析物种生活史性状与种子扩 散方式相关性的基础上, 以这 4 个生活史性状数据 为主要预测变量, 采用神经网络(neural network)、 决策树(decision tree)、费舍尔线性判别(Fisher linear discriminant)和支持向量机(support vector machine) 算法分别建立种子扩散方式预测模型, 试图找到一 种较为有效的判别方法, 为植物种子扩散方式研究 提供一定的参考。

\section{1 材料与方法}

\section{1 数据收集}

种子扩散方式数据来源于国内已发表的文献 (王桔红等, 2009; 李娟等, 2013; 雷霄等, 2015)及英
国邱园皇家植物园种子数据库 (http://data.kew.org/ $\mathrm{sid} /$ ), 生长型、株高、果实类型数据来源于 《中国 植物志》(http://frps.eflora.cn/), 种子质量数据来源于 中国西南野生生物种质资源库 (http://www.genobank.org/)。我们建立了一个具有500个物种的初始 数据集, 由于其中水扩散的物种所占比例较小, 在 本研究中未予以考虑。为了确保在随机抽样时每种 扩散方式的物种被抽取的概率相同, 需保证用于建 模的动物扩散、无助力扩散和风扩散方式的样本数 相同。由于在 500 个物种中风扩散的仅有 120 种, 因 此在建模时我们对其他 2 种传播方式也各随机抽取 了 120 种, 最后得到一个包括 360 个物种的数据集, 这些物种涵盖了 55 科 160 属, 乔、灌、草、藤所占比 例分别是 $26 \% 、 16 \% 、 54 \%$ 和 $4 \%$ 。

\section{2 性状分类标准的建立及相关性分析}

由于生长型、果实类型、种子扩散方式都是质 量性状, 而株高和种子质量为数量性状, 为了将数 据类型统一化，我们将每个生活史性状划分成若干 个分类水平(表1)。统一化后的 5 个植物生活史性状 为分类变量, 用 Gamma等级相关方法(用两个变量 之间同序对和异序对数量的差异反映变量间的相 关程度)进行相关分析, 并检验生长型、株高、果实 类型、种子质量与扩散方式这 5 个变量之间的相关 性, 为下一步的模型建立提供依据。

\section{3 建模方法}

为了建立有效的预测模型, 本研究分别采用了 神经网络(刘明同, 2001)、决策树(刘明同, 2001; 唐 华松和姚耀文，2001)、费希尔判别 ${ }^{1}$ 和支持向量机 (Cortes, 1995; 刘明同等, 2001) 4种算法进行建模。 将 360 个物种的 5 个生活史性状进行 $[0,1]$ 二进制赋 值后, 从中随机抽取 288 个物种数据(80\%)作为训练 样本建立判别模型, 其中生长型、株高、果实类型

(1) 赵丽娜 (2013) Fisher 判别法的研究及应用. 硕士学位论文, 东 北林业大学, 哈尔滨. 
和种子质量 4 个植物生活史性状作为自变量, 种子 扩散方式为因变量, 再用剩余的 72 个物种(20\%)作 为检测样本对模型进行检验, 并分析各判别模型对 扩散方式的预测能力。以 1,000 次随机抽样建模和检 验的总体平均正确率作为各模型的预测效果评价 指标, 得到最佳模型后进一步分析该模型对各扩散 方式的预测正确率。

统计分析均在R 3.2.3中进行, 神经网络模型用 nnet软件包, 决策树模型用 tree软件包, 费希尔线性 判别模型用MASS软件包, 支持向量机模型用e1071 软件包。

\section{2 结果}

\subsection{4 个植物生活史性状与种子扩散方式的相关性}

通过分析生长型、株高、果实类型、种子质量 及扩散方式间的相关性, 发现这5个生活史性状间 均有显著的相关关系 $(P<0.01)$ (表2)。其中生长型、 株高、果实类型、种子质量与扩散方式间都显著相 关 $(P<0.01)$, 说明这 4 个生活史性状能够用于预测 植物种子的扩散方式。

\section{2 用生活史性状预测种子扩散方式}

通过 1,000 次随机抽样建模和检验发现，4种模 型对种子扩散方式的预测效果分别是 $78.90 \%$ 、 $77.09 \% 、 77.81 \%$ 和 $78.14 \%$, 且以神经网络模型的预 测效果最好(变异系数为 $5.37 \%$ )。虽然决策树、费舍 尔线性判别和支持向量机模型也能达到较好的预 测效果, 但预测效果的变异系数均高于神经网络模 型(图1)。

对神经网络模型的预测结果进行进一步分析 发现, 该模型对动物扩散、无助力扩散和风扩散的 预测效果都较好(图2), 分别是 $81.32 \% 、 74.90 \%$ 和 $81.45 \%$ 。

\section{3 讨论}

本研究表明, 采用植物性状预测种子的传播方 式是可行的, 但采用合适的方法建立通用预测模型 存在一定的挑战。Hughes等(1994)在对有关种子扩 散方式的假说进行验证时指出, 用植物生活史性状 预测种子的扩散方式是种子生态学研究的重要手 段。植物各性状之间存在高度的相关性，传统的线 性模型预测效果不佳，而非线性的判别方法能够很
表2 5个植物生活史性状间的相关性

Table 2 Correlations between five life history traits of plants

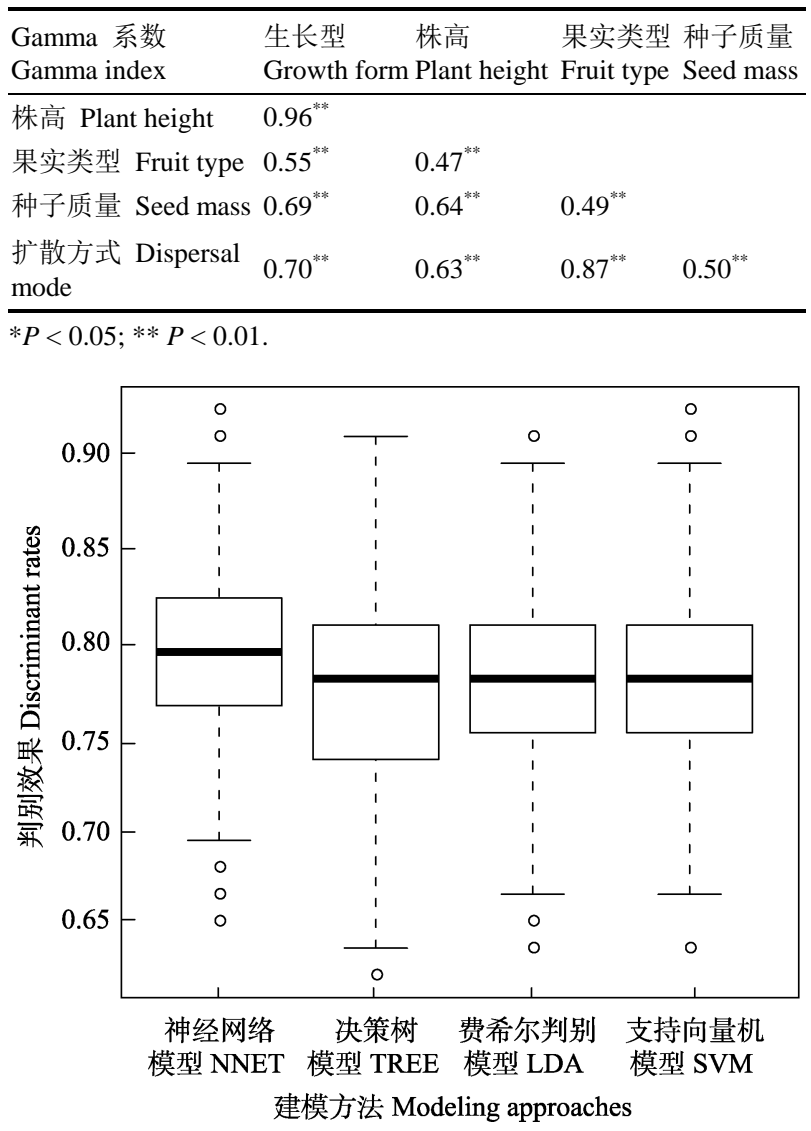

图14种模型对种子扩散方式的判别效果

Fig. 1 The discriminant rates of four models to seed dispersal modes. NNET, Neural network model; TREE, Decision tree model; LDA, Fisher linear discriminant model; SVM, Support vector machine model.

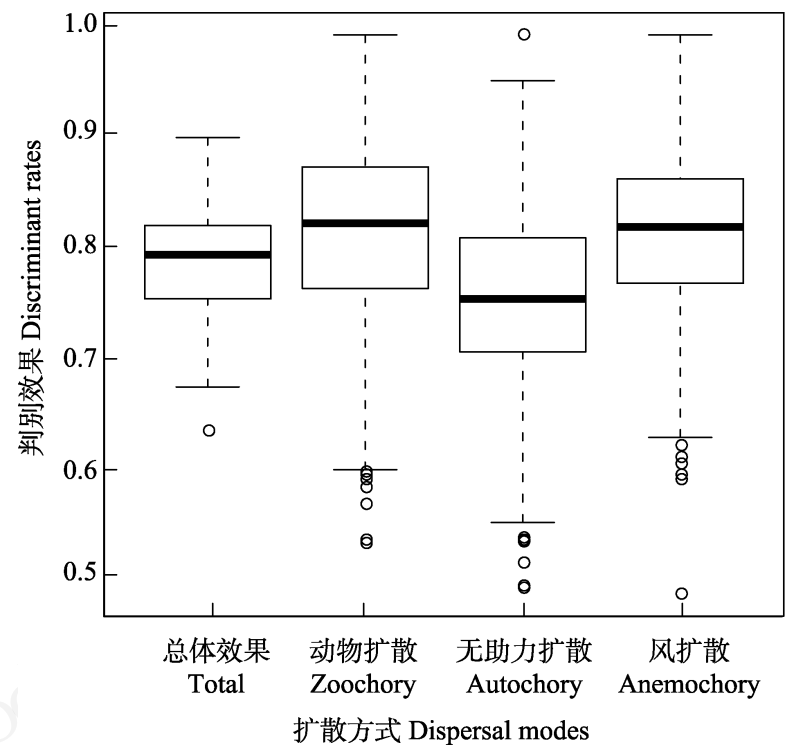

图2 神经网络模型对 3 种扩散方式的判别效果

Fig. 2 The discriminant rates of neural network model to three dispersal modes 
好地解决高度相关变量的分类问题。

本研究以生长型、株高、果实类型和种子质量 4 个性状为预测变量, 采用神经网络、决策树、费希 尔线性判别和支持向量机 4 种算法构建模型, 并对 模型的预测效果进行了检验, 结果显示这 4 种模型 对种子扩散方式的预测都有很好的效果。其中神经 网络模型的预测效果最好, 也最稳定, 可以作为今 后种子扩散方式预测的重要方法。4种模型的预测 效果差异主要决定于各模型的算法特点, 决策树模 型虽然可以处理非数值型的数据, 但由于本研究中 各变量有多个属性值, 导致该模型的预测能力较 差。支持向量机模型和费希尔线性判别模型的预测 效果稍好, 其算法原理都是将多维变量映射到新的 空间中, 以实现样本分类的目的, 但它们都只对二 类分类问题有较好的效果, 对多类分类的预测效果 也受到影响。而神经网络模型在建模过程中能够根 据输出值与实际值的误差对模型各参数进行调整, 模型的学习反馈能力较强, 所以预测效果较好。

本文所建立的预测模型对有单一扩散方式的 物种具有较强的预测能力, 而对有多种扩散方式的 物种的预测效果稍差。以神经网络模型为例, 虽然 该模型总体预测效果较好, 但对无助力扩散的预测 效果低于平均水平(图2)。这主要是因为种子质量小 于10 mg、果实为闭果的物种通常被认为通过无助 力扩散方式散布种子, 但由于其果实或种子具有特 殊结构, 它们也能够进行风扩散(Willson et al, 1990), 这些情况主要出现在菊科、罂粟科、毛茛科、 苋科和石竹科植物中。一些没有明显附属结构的种 子通常被认为是无助力扩散, 但事实上这些物种可 能是通过风扩散、动物扩散或者水扩散的(Thomson et al, 2010)。如萹蓄(Polygonum aviculare)可进行无 助力扩散和风扩散(van der Pijl, 1982), 橡胶树 (Hevea brasiliensis) 可进行无助力扩散和水扩散(van der Pijl, 1982; Turner, 2001; 周会平等, 2014), 但模 型对这些能够通过多种方式扩散种子的物种预测能 力较低。

除了对无助力扩散方式存在较高的误判率之 外, 神经网络模型对风扩散和动物扩散方式的预测 也存在一定的误判, 部分原因也是单个物种的种子 具有多种扩散方式。一些能够进行动物扩散的植物 种子也能进行风扩散, 如大狼杷草(Bidens frondosa) 和鬼针草 (B. pilosa) 等物种在模型中容易被判定为
风扩散(Mori \& Brown, 1998)。而有些依赖动物扩散 的物种, 如落葵(Basella alba)和木通(Akebia quinata) 等也能进行无助力扩散。将这些对模型预测效果具 有显著影响的物种剔除后建立的判别模型, 预测准 确率可达 $89.87 \%$, 证实了用于建模的数据质量会影 响模型预测效果。

为了提高每一种扩散方式的预测准确率, 可以 对每种扩散方式分别建立预测模型。如Thomson等 (2010)以澳大利亚悉尼周边区域的1,176种植物为研 究对象, 采用植被类型、生长型、株高、种子库类 型、种子质量、生活周期和生物类群等植物生活史 性状和生态学属性作为变量, 分别对每类种子扩散 方式构建线性混合效应模型, 然后用其他地区的数 据对模型进行检验，结果显示这些模型预测的最高 正确率为70\%。但Thomson等(2010)也指出, 针对单 一传播方式的预测模型会受到植被类型的影响, 其 结果在外推到其他植被类型时会受到制约。在本研 究中我们同时对 3 种扩散方式进行了预测, 后续将 针对每一种传播方式作进一步的预测模型研究。

此外, 建立模型时引入更多的预测变量也可以 改善预测效果, 如种子库类型、植被类型、冠幅等 (Hughes et al, 1994)。本研究中我们仅选用了4个容 易获取的植物生活史性状, 对于其他与种子扩散方 式相关的性状和生态学属性, 由于数据的匮乏而在 构建模型时并未包括在内, 使得预测变量所含信息 存在一定程度的不足, 可能对模型的预测效果有一 定影响。在今后的研究中可将种子库类型、生活史 周期等植物生活史性状及生态属性考虑在内。

总之, 种子扩散方式是一个重要的植物生活史 性状, 通过已有的生活史性状对其进行预测是今后 生态学研究的一个重要方向。本文用神经网络、决 策树、费希尔线性判别和支持向量机模型对种子扩 散方式的预测取得了较好效果, 可以作为今后种子 扩散方式预测的新方法。

\section{参考文献}

Baskin C, Baskin J (1998) Seeds: Ecology, Biogeography, and Evolution of Dormancy and Germination. Academic Press, San Diego.

Baskin C, Baskin J (2014) Seeds: Ecology, Biogeography, and Evolution of Dormancy and Germination, 2nd edn. Academic Press, San Diego.

Cain ML, Damman H, Muir A (1998) Seed dispersal and the 
Holocene migration of woodland herbs. Ecological Monograph, 68, 325-347.

Cain ML, Milligan BG, Strand AE (2000) Long-distance seed dispersal in plant populations. American Journal of Botany, 87, 1217-1227.

Clark JS, Macklin E, Wood L (1998) Stages and spatial scales of recruitment limitation in southern Appalachian forests. Ecological Monographs, 68, 157-166.

Cortes C (1995) Support-vector networks. Machine Learning, 20, 273-297.

Delectis Florae Reipublicae Popularis Sinicae Agendae Academicae Sinicae Edita (1979) Flora Reipublicae Popularis Sinicae. Science Press, Beijing. (in Chinese) [中国科学院中 国植物志编辑委员会 (1979) 中国植物志. 科学出版社, 北京.]

Hewitt N, Kellman M (2002) Tree seed dispersal among forest fragments. II. Dispersal abilities and biogeographical controls. Journal of Biogeography, 29, 351-363.

Hughes L, Dunlop M, French K, Leishman MR, Rice B, Rodgerson L, Westoby M (1994) Predicting dispersal spectra: a minimal set of hypotheses based on plant attributes. Journal of Ecology, 82, 933-950.

Jordano P, Forget PM, Lambert JE, Böhning-Gaese K, Traveset A, Wright SJ (2011) Frugivores and seed dispersal: mechanisms and consequences for biodiversity of a key ecological interaction. Biology Letters, 7, 321-323.

Lei X, Yang QS, Liu HM, Xing JZ, Wang XH (2015) Character of seed rain of species with different dispersal modes in Tiantong evergreen broad-leaved forest, Zhejiang Province. Journal of East China Normal University, 21, 122-132. (in Chinese with English abstract) [雷霄, 杨庆松, 刘何铭, 邢 九州, 王希华 (2015) 浙江天童常绿阔叶林不同扩散方 式物种种子雨的基本特征. 华东师范大学学报, 21 , 122-132.]

Leishman MR, Westoby M (1994) Hypotheses on seed size: tests using the semi-arid flora of western New South Wales, Australia. The American Naturalist, 143, 890-906.

Leishman MR, Westoby M, Jurado E (1995) Correlates of seed size variation: a comparison among five temperate floras. Journal of Ecology, 83, 517-529.

Li BH, Hao ZQ, Bin Y, Zhang J, Wang M (2012) Seed rain dynamics reveals strong dispersal limitation, different reproductive strategies and responses to climate in a temperate forest in Northeast China. Journal of Vegetation Science, 23, 271-279.

Li J, Guo C, Xiao ZS (2013) Fruit composition and seed dispersal strategies of woody plants in a Dujiangyan subtropical forest, Southwest China. Biodiversity Science, 21, 572-581. (in Chinese with English abstract) [李娟, 郭聪, 肖治术 (2013) 都江堰亚热带森林常见木本植物果实组 成与种子扩散策略. 生物多样性, 21, 572-581.]

Liu MT (2001) Data Mining Technology and Its Application. National Defense University Press, Beijing. (in Chinese) [刘
明同 (2001) 数据挖掘技术及其应用. 国防大学出版社, 北京.]

Moles AT, Ackerly DD, Webb CO, Tweddle JC, Dickie JB, Pitman AJ, Westoby M (2005) Factors that shape seed mass evolution. Proceedings of the National Academy of Sciences, USA, 102, 10540-10544.

Mori SA, Brown JL (1998) Epizoochorous dispersal by barbs, hooks, and spines in a lowland moist forest in central French Guiana. Brittonia, 50, 165-173.

Neubert MG, Caswell H (2000) Demography and dispersal: calculation and sensitivity analysis of invasion speed for structured populations. Ecology, 81, 1613-1628.

Tang HS, Yao YW (2001) Research on decision tree in data mining. Application Research of Computers, 18(8), 18-19, 22. (in Chinese with English abstract) [唐华松, 姚耀文 (2001) 数据挖掘中决策树算法的探讨. 计算机应用研究, 18(8), 18-19, 22]

Thompson K, Rabinowitz D (1989) Do big plants have big seeds? The American Naturalist, 133, 722-728.

Thomson FJ, Moles A T, Auld TD, Ramp D, Ren S, Kingsford RT (2010) Chasing the unknown: predicting seed dispersal. Journal of Ecology, 98, 1310-1318.

Thomson FJ, Moles AT, Auld TD, Kingsford RT (2011) Seed dispersal distance is more strongly correlated with plant height than with seed mass. Journal of Ecology, 99, 12991307.

Thuiller W, Albert C, Araujo MB, Berry PM, Cabeza M, Guisan A, Hickler T, Midgely GF, Paterson J, Schurr FM, Sykes MT, Zimmermann NE (2008) Predicting global change impacts on plant species' distributions: future challenges. Perspectives in Plant Ecology, Evolution and Systematics, 9, 137-152.

Turner IM (2001) The Ecology of Trees in the Tropical Rain Forest. Cambridge University Press, Cambridge.

van der Pijl L (1982) Principles of Dispersal in Higher Plants. Springer-Verlag, New York.

Wang JH, Du GZ, Cui XL, Zheng XF, Qi W (2009) Germination characteristics of 61 common woody species from the eastern Qinghai-Tibet Plateau of China and their life history correlates. Chinese Journal of Plant Ecology, 33, 171-179. (in Chinese with English abstract) [王桔红, 杜国祯, 崔现 亮, 郑秀芳, 齐威 (2009) 青藏高原东缘61种常见木本植 物种子萌发特性及其与生活史的关联. 植物生态学报, 33, 171-179.]

Westoby M, Jurado E, Leishman M (1992) Comparative evolutionary ecology of seed size. Trends in Ecology \& Evolution, 7, 368-372.

Westoby M, Leishman M, Lord JM (1996) Comparative ecology of seed size and dispersal. Philosophical Transactions of the Royal Society B: Biological Sciences, 351, 1309-1318.

Westoby M, Rice B, Howell J (1990) Seed size and plantgrowth form as factors in dispersal spectra. Ecology, 71, 1307-1315. 
Willson MF (1993) Dispersal mode, seed shadows, and colonization patterns. Plant Ecology, 107/108, 261-280.

Willson MF, Rice BL, Westoby M (1990) Seed dispersal spectra: a comparison of temperate plant-communities. Journal of Vegetation Science, 1, 547-562.

Yao B, Yu JP, Liu XJ, Mi XC, Ma KP (2015) Effect of seed traits on spatial aggregation of trees in a subtropical evergreen. Biodiversity Science, 23, 157-166. (in Chinese with English abstract) [姚蓓, 余建平, 刘晓娟, 米湘成, 马克平 (2015) 亚热带常绿阔叶林种子性状对木本植物聚集格局 的影响. 生物多样性, 23, 157-166.]

Yu SL, Chen HW, Li H (2007) Advances in ecology of mass. Journal of Plant Ecology (Chinese Version), 31, 989-997. (in Chinese with English abstract) [于顺利, 陈宏伟, 李晖 (2007) 种子重量的生态学研究进展. 植物生态学报, 31, 989-997.]

Zhang DY (2004) Plant Life History Evolution and Reproduc- tive Ecology. Science Press, Beijing. (in Chinese) [张大勇 (2004) 植物生活史进化与繁殖生态学. 科学出版社, 北京.]

Zheng JM, Sang WG, Ma KP (2004) Advances in model construction of anemochoric seed long distance dispersal. Acta Phytoecologica Sinica, 28, 414-425. (in Chinese with English abstract) [郑景明, 桑卫国, 马克平 (2004) 种子的长 距离风传播模型研究进展. 植物生态学报, 28, 414-425.]

Zhou HP, Chen GY, Yue H, Cun M (2014) Seed predation and dispersal of Hevea brasiliensis in Xishuangbanna introduction area. Chinese Journal of Ecology, 33, 2025-2030. (in Chinese with English abstract) [周会平, 陈国云, 岳海, 寸 明 (2014) 橡胶树在西双版纳引种区的种子捕食与散布. 生态学杂志, 33, 2025-2030.]

(责任编委: 谭敦炎 责任编辑: 黄祥忠)

\section{附录 Supplementary Material}

附录1 本文建模用 360 个物种名录

Appendix 1 Checklist of 360 species used in modeling in this study http://www.biodiversity-science.net/fileup/PDF/2017019-1.pdf 
郭志文，郑景明．用植物生活史性状预测种子扩散方式. 生物多样性，2017，25 (9)：966- 971. ht t p: //www. bi odi ver si ty- sci ence. net /CN/10. 17520/bi ods. 2017019

ID 科 Family

大戟科 Euphorbiaceae

冬青科 Ilex

冬青科 Ilex

冬青科 Ilex

5 冬青科 Ilex

6 冬青科 Ilex

7 冬青科 Ilex

8 冬青科 Ilex

9 冬青科 Ilex

10 冬青科 Ilex

11 冬青科 Ilex

12 冬青科 Ilex

13 冬青科 Ilex

14 冬青科 Ilex

15 冬青科 Ilex

16 冬青科 Ilex

17 冬青科 Ilex

18 冬青科 Ilex

9 冬青科 Ilex

20 冬青科 Ilex

21 冬青科 Ilex

22 冬青科 Ilex

23 豆科 Leguminosae

24 豆科 Leguminosae

25 豆科 Leguminosae

26 豆科 Leguminosae

27 豆科 Leguminosae

28 豆科 Leguminosae

29 豆科 Leguminosae

30 豆科 Leguminosae

31 豆科 Leguminosae

32 豆科 Leguminosae

33 豆科 Leguminosae

\author{
属 Genus \\ 种 Species
}

橡胶树属 Hevea

冬青属 Ilex

冬青属 Ilex

冬青属 Ilex

冬青属 Ilex

冬青属 Ilex

冬青属 Ilex

冬青属 Ilex

冬青属 Ilex

冬青属 Ilex

冬青属 Ilex

冬青属 Ilex

冬青属 Ilex

冬青属 Ilex

冬青属 Ilex

冬青属 Ilex

冬青属 Ilex

冬青属 Ilex

冬青属 Ilex

冬青属 Ilex

冬青属 Ilex

冬青属 Ilex

海红豆属 Adenanthera

合欢属 Albizia

金合欢属 Acacia

金合欢属 Acacia

金合欢属 Acacia

金合欢属 Acacia

决明属 Cassia

决明属 Cassia

决明属 Cassia

决明属 Cassia

决明属 Cassia
橡胶树 Hevea brasiliensis

大叶冬青 Ilex latifolia

冬青 Ilex chinensis

红河冬青 Ilex manneiensis

华中枸骨 Ilex centrochinensis

鲁甸冬青 Ilex ludianensis

落霜红 Ilex serrata

满树星 Ilex aculeolata

猫儿刺 Ilex pernyi

毛枝冬青 Ilex dasyclada

榕叶冬青 Ilex ficoidea

双核枸骨 Ilex dipyrena

四川冬青 Ilex szechwanensis

台湾冬青 Ilex formosana

铜光冬青 Ilex cupreonitens

细脉冬青 Ilex venosa

线叶冬青

小果冬青 Ilex micrococca

小核冬青 Ilex micropyrena

硬叶冬青 Ilex ficifolia

云南冬青 Ilex yunnanensis

长叶枸骨 Ilex georgei

海红豆 Adenanthera pavonina var.

microsperma

香合欢 Albizia odoratissima

阿拉伯金合欢 Acacia nilotica

儿茶 Acacia catechu

金合欢 Acacia farnesiana

银荆 Acacia dealbata

短叶决明 Cassia leschenaultiana

光叶决明 Cassia floribunda

槐叶决明 Cassia sophera

决明 Cassia tora

神黄豆 Cassia agnes
生活型

Growth form height (m) Fruit types

乔木

乔木

乔木

乔木

灌木

灌木

草本

灌木

灌木

灌木

乔木

乔木

乔木

草本

草本

雚木

乔木

灌木

乔木

乔木

灌木

乔木

乔木

乔木

乔木

乔木

乔木

草本

灌木

草本

草本

乔木

2

10

裂果

裂果
种子千粒重

Thousand 扩散方式

seed weight Dispersal mode

(g)

3809 自体传播

12.25 动物传播

8.34 动物传播

10.23 动物传播

8.25 动物传播

14.76 动物传播

3.24 动物传播

10.38 动物传播

18.02 动物传播

8.12 动物传播

7.82 动物传播

39.21 动物传播

14.53 动物传播

4.58 动物传播

8.34 自体传播

9.32 动物传播

12.54 动物传播

3.26 动物传播

0.94 动物传播

7.41 动物传播

7.56 动物传播

12.34 动物传播

234

动物传播

71.3

45

66.6

12.7

4.85

19.82

15.6

29.45

13.08

动物传播

动物传播

动物传播

动物传播

动物传播

自体传播

自体传播

自体传播

传播

自体传播 
郭志文, 郑景明. 用植物生活史性状预测种子扩散方式. 生物多样性, 2017，25 (9)：966- 971. ht t p: //www. bi odi ver si ty- sci ence. net /CN/10. 17520/bi ods. 2017019

\begin{tabular}{|c|c|c|c|c|c|c|c|c|}
\hline 34 & 豆科 Leguminosae & 决明属 Cassia & 铁刀木 Cassia siamea & 草本 & 10 & 裂果 & 9.21 & 自体传播 \\
\hline 35 & 豆科 Leguminosae & 决明属 Cassia & 长穗决明 Cassia didymobotrya & 灌木 & 3 & 裂果 & 45.16 & 自体传播 \\
\hline 36 & 豆科 Leguminosae & 野踠豆属 Vicia & 大花野踠豆 Vicia bungei & 草本 & 0.5 & 裂果 & 20.32 & 自体传播 \\
\hline 37 & 豆科 Leguminosae & 野碗豆属 Vicia & 东方野踠豆 Vicia japonica & 草本 & 1.2 & 裂果 & 18.82 & 自体传播 \\
\hline 38 & 豆科 Leguminosae & 野豌豆属 Vicia & 丕头菜 Vicia unijuga & 草本 & 1 & 裂果 & 13.6 & 自体传播 \\
\hline 39 & 豆科 Leguminosae & 野踠豆属 Vicia & 细叶野豌豆 Vicia tenuifolia & 草本 & 1 & 裂果 & 16.61 & 自体传播 \\
\hline 40 & 豆科 Leguminosae & 野豌豆属 Vicia & 新疆野豌豆 Vicia costata & 草本 & 0.8 & 裂果 & 31.43 & 自体传播 \\
\hline 41 & 豆科 Leguminosae & 野踠豆属 Vicia & 长柔毛野踠豆 Vicia villosa & 草本 & 1.5 & 裂果 & 17.52 & 自体传播 \\
\hline 42 & 豆科 Leguminosae & 鱼鳔槐属 Colutea & 鱼鳔槐 Colutea arborescens & 灌木 & 4 & 裂果 & 16.7 & 风传播 \\
\hline 43 & 豆科 Leguminosae & 紫穗槐属 Amorpha & 紫穗槐 Amorpha fruticosa & 灌木 & 4 & 裂果 & 9.7 & 动物传播 \\
\hline 44 & 杜英科 Elaeocarpaceae & 杜英属 Elaeocarpus & 杜英 Elaeocarpus decipiens & 乔木 & 10 & 肉质果 & 157.23 & 动物传播 \\
\hline 45 & 杜仲科 Eucommiaceae & 杜仲属 Eucommia & 杜仲 Eucommia ulmoides & 乔木 & 20 & 闭果 & 73 & 风传播 \\
\hline 46 & 凤仙花科 & 凤仙花属 Impatiens & 白花凤仙花 Impatiens wilsonii & 草本 & 0.6 & 裂果 & 8 & 自体传播 \\
\hline 47 & 凤仙花科 & 凤仙花属 Impatiens & 抱茎凤仙花 Impatiens amplexicaulis & 草本 & 0.4 & 裂果 & 3.2 & 自体传播 \\
\hline 48 & 凤仙花科 & 凤仙花属 Impatiens & 滇水金凤 Impatiens uliginosa & 草本 & 0.8 & 裂果 & 0.73 & 自体传播 \\
\hline 49 & 凤仙花科 & 凤仙花属 Impatiens & 耳叶凤仙花 Impatiens delavayi & 草本 & 0.4 & 裂果 & 2.67 & 自体传播 \\
\hline 50 & 凤仙花科 & 凤仙花属 Impatiens & 凤仙花 Impatiens balsamina & 草本 & 1 & 裂果 & 6.45 & 自体传播 \\
\hline 51 & 凤仙花科 & 凤仙花属 Impatiens & 华凤仙 Impatiens chinensis & 草本 & 0.6 & 裂果 & 1.83 & 自体传播 \\
\hline 52 & 凤仙花科 & 凤仙花属 Impatiens & 金凤花 Impatiens cyathiflora & 草木 & 1.7 & 裂果 & 0.81 & 自体传播 \\
\hline 53 & 凤仙花科 & 凤仙花属 Impatiens & 宽距凤仙花 Impatiens platyceras & 草本 & 1 & 裂果 & 8.67 & 自体传播 \\
\hline 54 & 凤仙花科 & 凤仙花属 Impatiens & 水金凤 Impatiens noli-tangere & 草本 & 0.7 & 裂果 & 5.36 & 自体传播 \\
\hline 55 & 凤仙花科 & 凤仙花属 Impatiens & 小花凤仙花 Impatiens parviflora & 草本 & 0.6 & 裂果 & 4.23 & 自体传播 \\
\hline 56 & 凤仙花科 & 凤仙花属 Impatiens & 总状凤仙花 Impatiens racemosa & 草本 & 0.6 & 裂果 & 1.5 & 自体传播 \\
\hline 57 & 海桐花科 Pittosporaceae & 海桐花属 Pittosporum & 海桐 Pittosporum tobira & 乔木 & 6 & 裂果 & 27.8 & 动物传播 \\
\hline 58 & 胡桃科 Juglandaceae & 枫杨属 Pterocarya & 枫杨 Pterocarya stenoptera & 乔木 & 30 & 闭果 & 76.42 & 风传播 \\
\hline 59 & 胡桃科 Juglandaceae & 枫杨属 Pterocarya & 甘肃枫杨 Pterocarya macroptera & 乔木 & 15 & 闭果 & 153.66 & 风传播 \\
\hline 60 & 胡桃科 Juglandaceae & 枫杨属 Pterocarya & 湖北枫杨 Pterocarya hupehensis & 乔木 & 30 & 闭果 & 84 & 风传播 \\
\hline 61 & 胡桃科 Juglandaceae & 枫杨属 Pterocarya & 云南枫杨 Pterocarya delavayi & 乔木 & 16 & 闭果 & 55.93 & 风传播 \\
\hline 62 & 胡桃科 Juglandaceae & 化香树属 Platycarya & 化香树 Platycarya strobilacea & 乔木 & 6 & 闭果 & 4.73 & 风传播 \\
\hline 63 & 胡桃科 Juglandaceae & 青钱柳属 Cyclocarya & 青钱柳 Cyclocarya paliurus & 乔木 & 30 & 闭果 & 156.34 & 风传播 \\
\hline 64 & 葫芦科 Cucurbitaceae & 喷瓜属 Ecballium & 喷瓜 Ecballium elaterium & 草本 & 1.5 & 肉质果 & 12.1 & 自体传播 \\
\hline 65 & $\begin{array}{l}\text { 虎皮楠科 } \\
\text { Daphniphyllaceae }\end{array}$ & 虎皮楠属 Daphniphyllum & 虎皮楠 Daphniphyllum oldhami & 乔木 & 10 & 肉质果 & 55.45 & 动物传播 \\
\hline 66 & 桦木科 Betulaceae & 鹅耳枥属 Carpinus & 雷公鹅耳枥 Carpinus viminea & 乔木 & 20 & 闭果 & 14.28 & 风传播 \\
\hline 67 & 桦木科 Betulaceae & 桦木属 Betula & 亮叶桦 Betula luminifera & 乔木 & 20 & 闭果 & 0.28 & 风传播 \\
\hline 68 & 金缕梅科 & 枫香树属 Liquidambar & 枫香树 Liquidambar formosana & 乔木 & 30 & 裂果 & 4.34 & 风传播 \\
\hline 69 & 景天科 Crassulaceae & 伽蓝菜属 Kalanchoe & 伽蓝菜 Kalanchoe laciniata & 草本 & 1 & 裂果 & 0.02 & 自体传播 \\
\hline 70 & 景天科 Crassulaceae & 伽蓝菜属 Kalanchoe & 燕子海棠 Kalanchoe blossfeldiana & 草本 & 0.6 & 裂果 & 0.01 & 自体传播 \\
\hline
\end{tabular}


郭志文，郑景明．用植物生活史性状预测种子扩散方式. 生物多样性，2017，25 (9)：966-971. ht t p: //www. bi odi ver si ty- sci ence. net /CN/10. 17520/bi ods. 2017019

\begin{tabular}{|c|c|c|}
\hline 71 & 景天科 Crassulaceae & 红景天属 Rhodiola \\
\hline 72 & 菊科 Compositae & 雏菊属 Bellis \\
\hline 73 & 菊科 Compositae & 垂头菊属 Cremanthodium \\
\hline 74 & 菊科 Compositae & 垂头菊属 Cremanthodium \\
\hline 75 & 菊科 Compositae & 大丽花属 Dahlia \\
\hline 76 & 菊科 Compositae & 风毛菊属 Saussurea \\
\hline 77 & 菊科 Compositae & 风毛菊属 Saussurea \\
\hline 78 & 菊科 Compositae & 风毛菊属 Saussurea \\
\hline 79 & 菊科 Compositae & 风毛菊属 Saussurea \\
\hline 80 & 菊科 Compositae & 风毛菊属 Saussurea \\
\hline 81 & 菊科 Compositae & 风毛菊属 Saussurea \\
\hline 82 & 菊科 Compositae & 风毛菊属 Saussurea \\
\hline 83 & 菊科 Compositae & 风毛菊属 Saussurea \\
\hline 84 & 菊科 Compositae & 风毛菊属 Saussurea \\
\hline 85 & 菊科 Compositae & 风毛菊属 Saussurea \\
\hline 86 & 菊科 Compositae & 风毛菊属 Saussurea \\
\hline 87 & 菊科 Compositae & 风毛菊属 Saussurea \\
\hline 88 & 菊科 Compositae & 风毛菊属 Saussurea \\
\hline 89 & 菊科 Compositae & 风毛菊属 Saussurea \\
\hline 90 & 菊科 Compositae & 风毛菊属 Saussurea \\
\hline 91 & 菊科 Compositae & 风毛菊属 Saussurea \\
\hline 92 & 菊科 Compositae & 风毛菊属 Saussurea \\
\hline 93 & 菊科 Compositae & 风毛菊属 Saussurea \\
\hline 94 & 菊科 Compositae & 风毛菊属 Saussurea \\
\hline 95 & 菊科 Compositae & 风毛菊属 Saussurea \\
\hline 96 & 菊科 Compositae & 风毛菊属 Saussurea \\
\hline 97 & 菊科 Compositae & 鬼针草属 Bidens \\
\hline 98 & 菊科 Compositae & 鬼针草属 Bidens \\
\hline 99 & 菊科 Compositae & 鬼针草属 Bidens \\
\hline 100 & 菊科 Compositae & 鬼针草属 Bidens \\
\hline 101 & 菊科 Compositae & 鬼针草属 Bidens \\
\hline 102 & 菊科 Compositae & 鬼针草属 Bidens \\
\hline 103 & 菊科 Compositae & 碱苑属 Tripolium \\
\hline 104 & 菊科 Compositae & 金光菊属 Rudbeckia \\
\hline 105 & 菊科 Compositae & 苓菊属 Jurinea \\
\hline 106 & 菊科 Compositae & 女苑属 Turczaninowia \\
\hline 107 & 菊科 Compositae & 匹菊属 Pyrethrum \\
\hline
\end{tabular}

71 景天科 Crassulaceae

垂头菊属 Cremanthodium

大丽花属 Dahlia

风毛菊属 Saussurea

Saussurea

风毛菊属 Saussurea

风毛菊属 Saussurea

风毛菊属 Saussurea

风毛菊属 Saussurea

风毛菊属 Saussurea

风毛菊属 Saussurea

风毛菊属 Saussurea

风毛菊属 Saussurea

女苑属 Turczaninowia
维菊 Bellis perennis 草本

草本

喜马拉雅垂头菊 Cremanthodium

decaisnei

羽裂垂头菊 Cremanthodium 草本

大丽花 Dahlia pinnata 草本

昂头风毛菊 Saussurea sobarocephala 草本

巴塘风毛菊 Saussurea limprichtii 草本

川西风毛菊 Saussurea dzeurensis 草本

打箭风毛菊 Saussurea tatsienensis 草本

倒披针叶风毛菊 Saussurea nimborum 草本

针苞雪莲 Saussurea nigrescens 草本

耳叶风毛菊 Saussurea neofranchetii 草本

喀什风毛菊 Saussurea kaschgarica 草本

丽江风毛菊 Saussurea Likiangensis 草本

林生风毛菊 Saussurea sylvatica草本

毛背雪莲 Saussurea pubifolia 草本

密毛风毛菊 Saussurea graminifolia 草本

锐齿风毛菊 Saussurea euodonta草本

洮河风毛菊 Saussurea pseudobullockii 乔木

西藏风毛菊 Saussurea tibetica草本

狭头风毛菊 Saussurea dielsiana草本

小尖风毛菊 Saussurea mucronulata 草本

鸢尾叶风毛菊 Saussurea romuleifolia 草本

长叶雪莲 Saussurea longifolia 草本

肿柄雪莲 Saussurea conica草本

加查雪兔子 Saussurea gyacaensis 草本

大狼杷草 Bidens frondosa 草本

鬼针草 Bidens pilosa 草本

狼杷草 Bidens tripartita草本

柳叶鬼针草 Bidens cernua 草本

婆婆针 Bidens bipinnata草本

小花鬼针草 Bidens parviflora草本

碱苑 Tripolium vulgare 草本

黑心金光菊 Rudbeckia hirta 草本

绥定苓菊 Jurinea suidunensis 草本

女苑 Turczaninowia fastigiata 草本

匹菊 Pyrethrum corymbiforme草本

\begin{tabular}{|c|c|c|c|}
\hline 0.25 & 裂果 & 0.16 & 自体传播 \\
\hline 0.2 & 闭果 & 0.1 & 风传播 \\
\hline 0.4 & 闭果 & 2.4 & 风传播 \\
\hline 0.2 & 闭果 & 2.68 & 风传播 \\
\hline 2 & 闭果 & 10.47 & 自体传播 \\
\hline 0.6 & 闭果 & 1.56 & 风传播 \\
\hline 0.15 & 闭果 & 2.65 & 风传播 \\
\hline 0.9 & 闭果 & 2.76 & 风传播 \\
\hline 0.3 & 闭果 & 3.04 & 风传播 \\
\hline 0.06 & 闭果 & 1.13 & 风传播 \\
\hline 0.45 & 闭果 & 2.12 & 风传播 \\
\hline 0.7 & 闭果 & 2.54 & 风传播 \\
\hline 0.25 & 闭果 & 2.29 & 风传播 \\
\hline 0.8 & 闭果 & 2.32 & 风传播 \\
\hline 0.8 & 闭果 & 2.36 & 风传播 \\
\hline 0.5 & 闭果 & 4.26 & 风传播 \\
\hline 0.2 & 闭果 & 3.03 & 风传播 \\
\hline 0.6 & 闭果 & 1.42 & 风传播 \\
\hline 0.3 & 闭果 & 2.89 & 风传播 \\
\hline 0.16 & 闭果 & 2.04 & 风传播 \\
\hline 0.8 & 闭果 & 2.12 & 风传播 \\
\hline 0.2 & 闭果 & 1.73 & 风传播 \\
\hline 0.35 & 闭果 & 3.94 & 风传播 \\
\hline 0.3 & 闭果 & 3.46 & 风传播 \\
\hline 0.45 & 闭果 & 2.68 & 风传播 \\
\hline 0.1 & 闭果 & 1.38 & 风传播 \\
\hline 1.2 & 闭果 & 2.76 & 动物传播 \\
\hline 1 & 闭果 & 2.96 & 动物传播 \\
\hline 1.5 & 闭果 & 2.87 & 动物传播 \\
\hline 0.9 & 闭果 & 3.7 & 动物传播 \\
\hline 1.2 & 闭果 & 2.93 & 动物传播 \\
\hline 0.9 & 闭果 & 3.24 & 动物传播 \\
\hline 0.8 & 闭果 & 0.28 & 风传播 \\
\hline 1 & 闭果 & 0.55 & 风传播 \\
\hline 0.3 & 闭果 & 7.89 & 风传播 \\
\hline 1 & 闭果 & 0.1 & 风传播 \\
\hline 1 & 闭果 & 0.24 & 风传播 \\
\hline
\end{tabular}


郭志文，郑景明．用植物生活史性状预测种子扩散方式．生物多样性，2017，25 (9)：966-971. ht t p: //www. bi odi ver si ty- sci ence. net /CN/10. 17520/bi ods. 2017019

108 菊科 Compositae

109 菊科 Compositae

110 菊科 Compositae

111 菊科 Compositae

112 菊科 Compositae

113 菊科 Compositae

114 菊科 Compositae

115 菊科 Compositae

116 菊科 Compositae

117 菊科 Compositae

118 菊科 Compositae

119 菊科 Compositae

120 菊科 Compositae

121 菊科 Compositae

122 苦木科 Simaroubaceae

123 蜡梅科 Calycanthacea

124 藜科 Chenopodiaceae

125 藜科 Chenopodiaceae

126 藜科 Chenopodiaceae

127 藜科 Chenopodiaceae

128 藜科 Chenopodiaceae

129 藜科 Chenopodiaceae

130 藜科 Chenopodiaceae

131 蓼科 Polygonaceae

132 蓼科 Polygonaceae

133 蓼科 Polygonaceae

134 蓼科 Polygonaceae

135 蓼科 Polygonaceae

136 蓼科 Polygonaceae

137 蓼科 Polygonaceae

138 蓼科 Polygonaceae

139 蓼科 Polygonaceae

140 蓼科 Polygonaceae

141 蓼科 Polygonaceae

142 蓼科 Polygonaceae

143 蓼科 Polygonaceae
蒲公英属 Taraxacum

蒲公英属 Taraxacum

山芫荽属 Cotula

茼蒿属 Chrysanthemum

茼蒿属 Chrysanthemum

万寿菊属 Tagetes

莴苣属 Lactuca

线叶菊属 Filifolium

小甘菊属 Cancrinia

野茼蒿属 Crassocephalum

一点红属 Emilia

一枝黄花属 Solidago

泽兰属 Eupatorium

紫苑属 Aster

苦树属 Picrasma

蜡梅属 Chimononthus

地肤属 Kochia

碱蓬属 Suaeda

藜属 Chenopodium

藜属 Chenopodium

藜属 Chenopodium

藜属 Chenopodium

沙蓬属 Agriophyllum

大黄属 Rheum

大黄属 Rheum

大黄属 Rheum

何首乌属 Fallopia

虎杖属 Reynoutria

蓼属 Polygonum

蓼属 Polygonum

蓼属 Polygonum

蓼属 Polygonum

蓼属 Polygonum

蓼属 Polygonum

蓼属 Polygonum

蓼属 Polygonum
川甘蒲公英 Taraxacum lugubre

尖角蒲公英 Taraxacum pingue

芫荌菊 Cotula anthemoides

南茼蒿 Chrysanthemum segetum

茼蒿 Chrysanthemum coronarium

万寿菊 Tagetes erecta

长叶莴菅 Lactuca dolichophylla

线叶菊 Filifolium sibiricum

小甘菊 Cancrinia discoidea

野泀蒿 Crassocephalum crepidioides

小一点红 Emilia prenanthoidea

加拿大一枝黄花 Solidago canadensis

台湾泽兰 Eupatorium formosanum

灰毛紫苑 Aster polius

苦树 Picrasma quassioides

蜡梅 Chimononthus praecox

地肤 Kochia scoparia

碱蓬 Suaeda glauca

灰绿藜 Chenopodium glaucum

尖头叶㢣 Chenopodium acuminatum

菊叶香藜 Chenopodium foetidum

小㢣 Chenopodium serotinum

沙蓬 Agriophyllum squarrosum

波叶大黄 Rheum rhabarbarum

药用大黄 Rheum officinale

掌叶大黄 Rheum palmatum

何首乌 Fallopia multiflora

虎杖 Reynoutria japonica

萹蓄 Polygonum aviculare

萹蓄（变种） Plygonum aviculare

var. aviculare

杜板归 Polygonum perfoliatum

红蓼 Polygonum orientale

火炭母 Polygonum chinense

蓼蓝. Polygonum tinctorium

绵毛酸模叶蓼 Polygonum

lapathifolium var. lanatum

尼泊尔蓼 Polygonum nepalense

草本
草本
草本
草本
乔木
草本
草本
草本
草本
草本
草本
草本
木质藤本
草本
乔木
灌木
草本
草本
草本
草本
草本
草本
草本
草本
草本
草本
草本
草本
草本
草本
草本
草本
草本
草本
草本
草本

闭果

闭果

闭果

闭果

闭果

闭果

闭果

闭果

闭果

闭果

闭果

闭果

闭果

肉质果

闭果

闭果

闭果

闭果

闭果

闭果

闭果

闭果

闭果

闭果

闭果

闭果

闭果

闭果

闭果

闭果

闭果

闭果

闭果

闭果

闭果

$\begin{array}{ll}1.06 & \text { 风传播 } \\ 0.5 & \text { 风传播 } \\ 1.47 & \text { 风传播 } \\ 1.47 & \text { 风传播 } \\ 1.7 & \text { 风传播 } \\ 1.8 & \text { 风传播 } \\ 0.68 & \text { 风传播 } \\ 0.27 & \text { 风传播 } \\ 0.18 & \text { 风传播 } \\ 0.25 & \text { 风传播 } \\ 0.32 & \text { 风传播 } \\ 0.1 & \text { 风传播 } \\ 0.19 & \text { 风传播 } \\ 0.34 & \text { 风传播 } \\ 34.91 & \text { 动物传播 } \\ 210 & \text { 自体传播 } \\ 0.71 & \text { 自体传播 } \\ 1.82 & \text { 自体传播 } \\ 0.24 & \text { 自体传播 } \\ 0.42 & \text { 自体传播 } \\ 0.13 & \text { 自体传播 } \\ 0.38 & \text { 自体传播 } \\ 1.6 & \text { 自体传播 } \\ 24 & \text { 风传播 } \\ 12.2 & \text { 风传播 } \\ 10 & \text { 风传播 } \\ 2 & \text { 风传播 } \\ 5 & \text { 风传播 } \\ 2.7 & \text { 自体传播 } \\ 1.3 & \text { 自体传播 } \\ 20.72 & \text { 动物传播 } \\ 8.5 & \text { 动物传播 } \\ 4.7 & \text { 动物传播 } \\ 3 & \text { 熖 } \\ & \end{array}$

1.19

风传播

自体传播 
郭志文, 郑景明. 用植物生活史性状预测种子扩散方式. 生物多样性, 2017, 25 (9)：966- 971. ht t p: //www. bi odi ver si ty- sci ence. net /CN/10. 17520/bi ods. 2017019

144 蓼科 Polygonaceae

145 蓼科 Polygonaceae

146 蓼科 Polygonaceae

147 蓼科 Polygonaceae

148 苶科 Polygonaceae

149 蓼科 Polygonaceae

150 蓼科 Polygonaceae

151 蓼科 Polygonaceae

152 蓼科 Polygonaceae

153 蓼科 Polygonaceae

154 萝藦科 Asclepiadaceae

155 萝摩科 Asclepiadaceae

156 萝藦科 Asclepiadaceae

157 萝摩科 Asclepiadaceae

158 萝藦科 Asclepiadaceae

159 落葵科 Basellaceae

160 马鞭草科 Verbenaceae

161 马齿苋科 Portulacacea

162 马齿苋科 Portulacacea

163 马齿苋科 Portulacacea

164 马齿苋科 Portulacacea

165 马齿苋科 Portulacacea

166 陇牛儿苗科

167 毛莨科 Ranunculaceae

168 毛莨科 Ranunculaceae

169 毛莨科 Ranunculaceae

170 毛莨科 Ranunculaceae

171 毛茛科 Ranunculaceae

172 毛莨科 Ranunculaceae

173 毛茛科 Ranunculaceae

174 毛茛科 Ranunculaceae

175 毛茛科 Ranunculaceae

176 毛莨科 Ranunculaceae

177 毛茛科 Ranunculaceae

178 毛莨科 Ranunculaceae

179 毛莨科 Ranunculaceae

180 毛莨科 Ranunculaceae
蓼属 Polygonum

蓼属 Polygonum

蓼属 Polygonum

蓼属 Polygonum

蓼属 Polygonum

苶属 Polygonum

菾麦属 Fagopyrum

养麦属 Fagopyrum

酸模属 Rumex

酸模属 Rumex

我鸟线藤属 Cynanchum

杜柳属 Periploca

杜柳属 Periploca

牛奶菜属 Marsdenia

醉魂藤属 Heterostemma

落葵属 Basella

大青属 Clerodendrum

马齿苋属 Portulaca

马齿苋属 Portulaca

马齿苋属 Portulaca

马齿苋属 Portulaca

土人参属 Talinum

陇牛儿苗属 Erodium

翠雀属 Delphinium

耧斗菜属 Aquilegia

苟药属 Paeonia

苟药属 Paeonia

药药属 Paeonia

铁线莲属 Clematis

铁线莲属 Clematis

铁线莲属 Clematis

铁线莲属 Clematis

铁线莲属 Clematis

铁线莲属 Clematis

铁线莲属 Clematis

铁线莲属 Clematis

铁线莲属 Clematis
拳参 Polygonum bistorta

水蓼 Polygonum hydropiper

酸模叶蓼 Polygonum lapathifolium

稀花蓼 Polygonum dissitiflorum

显花蓼 Polygonum japonicum var.

conspicuum

长鬃蓼 Polygonum longisetum

金菾麦 Fagopyrum dibotrys

菾麦 Fagopyrum esculentum

酸模 Rumex acetosa

羊蹄 Rumex japonicus

白薇 Cynanchum atratum

杜柳 Periploca sepium

黑龙骨 Periploca forrestii

圆头牛奶菜 Marsdenia tsaiana

心叶醉魂藤 Heterostemma siamicum

落葵 Basella alba

大青 Clerodendrum cyrtophyllum

大花马齿苋 Portulaca grandiflora

马齿苋 Portulaca oleracea

沙生马齿苋 Portulaca psammotropha

四瓣马齿苋 Portulaca quadrifida

土人参 Talinum paniculatum

陇牛儿苗 Erodium stephanianum

翠雀 Delphinium grandiflorum

华北耧斗菜 Aquilegia yabeana

牡丹 Paeonia suffruticosa

药药 Paeonia lactiflora

新疆苻药 Paeonia sinjiangensis

大叶铁线莲 Clematis heracleifolia

黄花铁线莲 Clematis intricata

金毛铁线莲 Clematis chrysocoma

毛芯铁线莲 Clematis lasiandra

毛柱铁线莲 Clematis meyeniana

太行铁线莲 Clematis kirilowi

威灵仙 Clematis chinensis

五叶铁线莲 Clematis quinquefoliolata

西伯利亚铁线莲 Clematis sibirica

\begin{tabular}{ll} 
草本 & 3 \\
草本 & 0.7 \\
草本 & 0.9 \\
草本 & 1 \\
草本 & 0.8 \\
草本 & 0.6 \\
草本 & 1 \\
草本 & 0.9 \\
草本 & 1 \\
草本 & 1 \\
草本 & 0.5 \\
草本 & 8 \\
木质藤本 & 5 \\
木质藤本 & 5 \\
木质藤本 & 5 \\
灌木 & 3 \\
灌木 & 10 \\
草本 & 0.23 \\
草本 & 0.5 \\
草本 & 0.4 \\
乔木 & 0.3 \\
草本 & 0.6 \\
草本 & 0.4 \\
草本 & 0.65 \\
草本 & 0.6 \\
灌木 & 2 \\
草本 & 0.7 \\
草本 & 1.2 \\
灌木 & 3.5 \\
木质藤本 & 2 \\
木质藤本 & 2 \\
木质藤本 & 2.5 \\
木质藤本 & 2 \\
草本 & 2.3 \\
木质藤本 & 2 \\
木质藤本 & 2.5 \\
木质藤本 & 3 \\
& \\
\hline & 2 \\
\hline & 2 \\
\hline & 2 \\
\hline
\end{tabular}

自体传播

自体传播

风传播

风传播

自体传播

自体传播

动物传播

动物传播

风传播

风传播

风传播

风传播

风传播

风传播

$\begin{array}{lll}\text { 裂果 } & 3.26 & \text { 风传播 } \\ \text { 闭果 } & 36 & \text { 动物传播 }\end{array}$

肉质果 38.56 动物传播

裂果 0.4 自体传播

裂果 0.18 自体传播

裂果 0.22 自体传播

裂果 0.23 动物传播

肉质果 20.13 自体传播

裂果 12.34 自体传播

裂果 1.24 自体传播

裂果 1.4 自体传播

裂果 198 自体传播

裂果 161 自体传播

裂果 186 自体传播

闭果 6.7 风传播

闭果 1.45 风传播

闭果 1.21 风传播

闭果 0.87 风传播

闭果 3.45 风传播

闭果 3.78 风传播

闭果 8.2 风传播

闭果 7.53 风传播

闭果 1.43 风传播 
郭志文，郑景明. 用植物生活史性状预测种子扩散方式. 生物多样性，2017，25 (9)：966- 971. ht t p: //www. bi odi ver si ty- sci ence. net /CN/10. 17520/bi ods. 2017019

\begin{tabular}{|c|c|c|}
\hline 181 & 毛茛科 Ranunculaceae & 铁线莲属 Clematis \\
\hline 182 & 毛莨科 Ranunculaceae & 乌头属 Aconitum \\
\hline 183 & 毛莨科 Ranunculaceae & 乌头属 Aconitum \\
\hline 184 & 毛莨科 Ranunculaceae & 乌头属 Aconitum \\
\hline 185 & 毛茛科 Ranunculaceae & 乌头属 Aconitum \\
\hline 186 & 毛莨科 Ranunculaceae & 乌头属 Aconitum \\
\hline 187 & 毛茛科 Ranunculaceae & 乌头属 Aconitum \\
\hline 188 & 毛茛科 Ranunculaceae & 乌头属 Aconitum \\
\hline 189 & 毛茛科 Ranunculaceae & 乌头属 Aconitum \\
\hline 190 & 毛莨科 Ranunculaceae & 乌头属 Aconitum \\
\hline 191 & 毛莨科 Ranunculaceae & 乌头属 Aconitum \\
\hline 192 & 毛茛科 Ranunculaceae & 乌头属 Aconitum \\
\hline 193 & 毛茛科 Ranunculaceae & 乌头属 Aconitum \\
\hline 194 & 毛茛科 Ranunculaceae & 乌头属 Aconitum \\
\hline 195 & 毛莨科 Ranunculaceae & 乌头属 Aconitum \\
\hline 196 & 毛茛科 Ranunculaceae & 乌头属 Aconitum \\
\hline 197 & 毛茛科 Ranunculaceae & 乌头属 Aconitum \\
\hline 198 & 毛茛科 Ranunculaceae & 乌头属 Aconitum \\
\hline 199 & 毛茛科 Ranunculaceae & 乌头属 Aconitum \\
\hline 200 & 毛茛科 Ranunculaceae & 乌头属 Aconitum \\
\hline 201 & 毛茛科 Ranunculaceae & 乌头属 Aconitum \\
\hline 202 & 毛茛科 Ranunculaceae & 乌头属 Aconitum \\
\hline 203 & 毛茛科 Ranunculaceae & 乌头属 Aconitum \\
\hline 204 & 木兰科 Magnoliaceae & 八角属 Illicium \\
\hline 205 & 木通科 Lardizabalaceae & 木通属 Akebia \\
\hline 206 & 木通科 Lardizabalaceae & 木通属 Akebia \\
\hline 207 & 木犀科 Oleaceae & 木犀属 Osmanthus \\
\hline 208 & 漆树科 Anacardiaceae & 南酸杳属 Choerospondic \\
\hline 209 & 漆树科 Anacardiaceae & 漆属 Toxicodendron \\
\hline 210 & 漆树科 Anacardiaceae & 漆属 Toxicodendron \\
\hline 211 & 漆树科 Anacardiaceae & 盐肤木属 Rhus \\
\hline 212 & 槭树科 Aceraceae & 金钱槭属 Dipteronia \\
\hline 213 & 槭树科 Aceraceae & 槭属 Acer \\
\hline 214 & 槭树科 Aceraceae & 槭属 Acer \\
\hline 215 & 槭树科 Aceraceae & 槭属 Acer \\
\hline 216 & 槭树科 Aceraceae & 槭属 Acer \\
\hline 217 & Aceraceae & 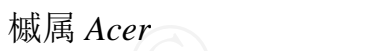 \\
\hline 218 & Aceraceae & 属 Acer \\
\hline
\end{tabular}

\begin{tabular}{|c|c|}
\hline 长花铁线莲 Clematis rehderiana & 木质藤本 \\
\hline 滇北乌头 Aconitum iochanicum & 草本 \\
\hline 滇南草乌 Aconitum austroyunnanense & 草本 \\
\hline 短柄乌头 Aconitum brachypodum & 草本 \\
\hline 多根乌头 Aconitum karakolicum & 草本 \\
\hline 甘青乌头 Aconitum tanguticum & 草本 \\
\hline 高乌头 Aconitum sinomontanum & 草本 \\
\hline 工布乌头 Aconitum kongboense & 草本 \\
\hline 花葶乌头 Aconitum scaposum & 草本 \\
\hline 黄毛乌头 Aconitum chrysotrichum & 草本 \\
\hline 剑川乌头 Aconitum handelianum & 草本 \\
\hline 江孜乌头 Aconitum ludlowii & 草本 \\
\hline 空茎乌头 Aconitum apetalum & 草本 \\
\hline 墨脱乌头 Aconitum elliotii & 草本 \\
\hline 全裂乌头 Aconitum pseudodivaricatum & 草本 \\
\hline 匙苞乌头 Aconitum spathulatum & 草本 \\
\hline 乌头 Aconitum carmichaeli & 草本 \\
\hline 显柱乌头 Aconitum stylosum & 草本 \\
\hline 新都桥乌头 Aconitum tongolense & 草本 \\
\hline 新疆乌头 Aconitum sinchiangense & 草本 \\
\hline 展喙乌头 Aconitum novoluridum & 草本 \\
\hline 长序乌头 Aconitum dolichostachyum & 草本 \\
\hline 直序乌头 Aconitum richardsonianum & 草本 \\
\hline 八角 Illicium verum & 乔木 \\
\hline 木通 Akebia quinata & 木质藤本 \\
\hline 三叶木通 Akebia trifoliata & 木质藤本 \\
\hline 木犀 Osmanthus fragrans & 乔木 \\
\hline 南酸束 Choerospondias axillaris & 乔木 \\
\hline 木蜡树 Toxicodendron sylvestre & 乔木 \\
\hline 漆树 Toxicodendron vernicifluum & 乔木 \\
\hline 盐肤木 Rhus chinensis & 灌木 \\
\hline 金钱槭 Dipteronia sinensis & 乔木 \\
\hline 茶条槭 Acer ginnala & 乔木 \\
\hline 独龙槭 Acer taronense & 乔木 \\
\hline 房县槭 Acer franchetii & 乔木 \\
\hline 飞蛾槭 Acer oblongum & 乔木 \\
\hline 鸡爪槭 Acer palmatum & 乔木 \\
\hline 建始槭 Acer henryi & 乔木 \\
\hline
\end{tabular}

\begin{tabular}{|c|c|c|}
\hline 闭果 & 2.96 & 风传播 \\
\hline 裂果 & 0.86 & 自体传播 \\
\hline 裂果 & 1.99 & 自体传播 \\
\hline 裂果 & 0.86 & 自体传播 \\
\hline 裂果 & 0.93 & 自体传播 \\
\hline 裂果 & 0.98 & 自体传播 \\
\hline 裂果 & 2.65 & 自体传揞 \\
\hline 裂果 & 1.56 & 自体传播 \\
\hline 裂果 & 0.96 & 自体传播 \\
\hline 裂果 & 0.82 & 自体传播 \\
\hline 裂果 & 1.92 & 自体传播 \\
\hline 裂果 & 1.22 & 自体传揞 \\
\hline 裂果 & 2.08 & 自体传 \\
\hline 裂果 & 1.56 & 自体传 \\
\hline 裂果 & 1.69 & 自体传播 \\
\hline 裂果 & 0.98 & 自体传f \\
\hline 裂果 & 2.5 & 自体传拉 \\
\hline 裂果 & 0.95 & 自体传 \\
\hline 裂果 & 1.42 & 自体传拐 \\
\hline 裂果 & 2.47 & 自体传 \\
\hline 裂果 & 1.51 & 自体传 \\
\hline 裂果 & 2.09 & 自体传 \\
\hline 裂果 & 1.53 & 自体传 \\
\hline 裂果 & 64.5 & 自体传 \\
\hline 裂果 & 35 & 动物传 \\
\hline 裂果 & 46 & 动物传 \\
\hline 肉质果 & 112.42 & 动物传 \\
\hline 肉质果 & 2200 & 动物传 \\
\hline 肉质果 & 14.9 & 动物传 \\
\hline 肉质果 & 44.46 & 动物传 \\
\hline 肉质果 & 60 & 动物传播 \\
\hline 裂果 & 24.28 & 风传播 \\
\hline 闭果 & 23.42 & 风传播 \\
\hline 闭果 & 25.08 & 风传播 \\
\hline & 77.09 & 风传播 \\
\hline & 31.09 & 风传播 \\
\hline & 32.89 & 风传播 \\
\hline & 24.26 & 风传播 \\
\hline
\end{tabular}

风传播 风体传播 自体传播 体传播 自体传播 体传播 体传播 自体传播 自体传播 自体传播 自体传播 自体传播 自体传播 自体传播 物传播 物传播 物传播 动物传播

闭果

风传播 
郭志文, 郑景明. 用植物生活史性状预测种子扩散方式. 生物多样性，2017，25 (9)：966- 971. ht t p: //www. bi odi ver si ty- sci ence. net /CN/10. 17520/bi ods. 2017019

\begin{tabular}{|c|c|c|}
\hline 219 & 槭树科 Aceraceae & 槭属 Acer \\
\hline 220 & 槭树科 Aceraceae & 槭属 Acer \\
\hline 21 & 槭树科 Aceraceae & 槭属 Acer \\
\hline 22 & 槭树科 Aceraceae & 槭属 Acer \\
\hline 23 & 槭树科 Aceraceae & 槭属 Acer \\
\hline 24 & 槭树科 Aceraceae & 槭属 Acer \\
\hline 225 & 槭树科 Aceraceae & 槭属 Acer \\
\hline 26 & 槭树科 Aceraceae & 槭属 Acer \\
\hline 227 & 槭树科 Aceraceae & 槭属 Acer \\
\hline 228 & 槭树科 Aceraceae & 槭属 Acer \\
\hline 229 & 槭树科 Aceraceae & 槭属 Acer \\
\hline 230 & 菩薇科 Rosaceae & 地榆属 Sanguisorba \\
\hline 231 & 菩薇科 Rosaceae & 龙芽草属 Agrimonia \\
\hline 232 & 蓄薇科 Rosaceae & 枇杷属 Eriobotrya \\
\hline 233 & 蓄薇科 Rosaceae & 蓄薇属 Rosa \\
\hline 234 & 薔薇科 Rosaceae & 蓄薇属 Rosa \\
\hline 235 & 蓠薇科 Rosaceae & 蓄薇属 Rosa \\
\hline 236 & 蓄薇科 Rosaceae & 蓄薇属 Rosa \\
\hline 237 & 蓄薇科 Rosaceae & 蛇莓属 Duchesnea \\
\hline 238 & 菩薇科 Rosaceae & 悬钩子属 Rubus \\
\hline 239 & 蓄薇科 Rosaceae & 悬钩子属 Rubus \\
\hline 240 & 蓄薇科 Rosaceae & 樱属 Cerasus \\
\hline 241 & 忍冬科 Caprifoliaceae & 忍冬属 Lonicera \\
\hline 242 & 忍冬科 Caprifoliaceae & 忍冬属 Lonicera \\
\hline 243 & 忍冬科 Caprifoliaceae & 忍冬属 Lonicera \\
\hline 244 & 忍冬科 Caprifoliaceae & 忍冬属 Lonicera \\
\hline 245 & 忍冬科 Caprifoliaceae & 忍冬属 Lonicera \\
\hline 246 & 忍冬科 Caprifoliaceae & 忍冬属 Lonicera \\
\hline 247 & 忍冬科 Caprifoliaceae & 忍冬属 Lonicera \\
\hline 248 & 忍冬科 Caprifoliaceae & 忍冬属 Lonicera \\
\hline 249 & 忍冬科 Caprifoliaceae & 忍冬属 Lonicera \\
\hline 250 & 忍冬科 Caprifoliaceae & 忍冬属 Lonicera \\
\hline 251 & 桑寄生科 Loranthaceae & 葪寄生属 Viscum \\
\hline 252 & 桑寄生科 Loranthaceae & 桷寄生属 Viscum \\
\hline 253 & 桑科 Moraceae & 构树属 Broussonetia \\
\hline 254 & 桑科 Moraceae & 葎草属 Humulus \\
\hline 255 & 桑科 Moraceae & 榕属 Ficus \\
\hline 256 & 桑科 Moraceae & 桑属 Morus \\
\hline
\end{tabular}

219 槭树科 Aceraceae

橴树科 Aceraceae

23 槭树科 Aceraceae

槭树科 Aceraceae

232 菩微科 Rosaceae

236 萻薇科 Rosaceae

240 蓄薇科 Rosaceae

256 桑科 Moraceae
丽江槭 Acer forrestii

罗浮槭 Acer fabri

毛脉槭 Acer pubinerve

七裂槭 Acer heptalobum

青皮槭 Acer cappadocicum

三角槭 Acer buergerianum

深灰槭 Acer caesium

五裂槭 Acer oliverianum

元宝槭 Acer truncatum

长尾槭 Acer caudatum

中华槭 Acer sinense

地榆 Sanguisorba officinalis

龙芽草 Agrimonia pilosa

枇杷 Eriobotrya japonica

金樱子 Rosa laevigata

木香花 Rosa banksiae

七姊妹 Rosa multiflora

小果蓄薇 Rosa cymosa

蛇莓 Duchesnea indica

高粱泡 Rubus lambertianus

山莓 Rubus corchorifolius

樱桃 Cerasus pseudocerasus

凹叶忍冬 Lonicera retusa

淡红忍冬 Lonicera acuminata

菰腺忍冬 Lonicera hypoglauca

红脉忍冬 Lonicera nervosa

棘枝忍冬 Lonicera spinosa

金银忍冬 Lonicera maackii

蓝果忍冬 Lonicera caerulea

微毛忍冬 Lonicera cyanocarpa

长白忍冬 Lonicera ruprechtiana

长距忍冬 Lonicera calcarata

白果葪寄生 Viscum album

檞寄生 Viscum coloratum

构树 Broussonetia papyifera

葎草 Humulus scandens

异叶榕 Ficus heteromorpha

桑 Morus alba

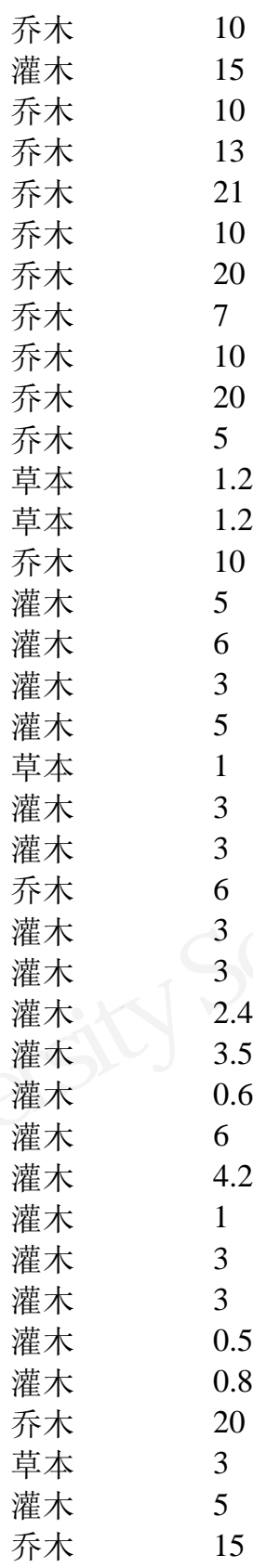

闭果

闭果

闭果

闭果

闭果

闭果

闭果

闭果

闭果

闭果

闭果

闭果

闭果

肉质果

闭果

闭果

闭果

闭果

闭果

闭果

闭果

肉质果

肉质果

肉质果

肉质果

肉质果

肉质果

肉质果

肉质果

肉质果

肉质果

肉质果

肉质果

肉质果

闭果

闭果

闭果

肉质果
24.19

风传播

35.82

40.36

37.55

46.09

20.71

116.38

29.68

31.26

29.25

32.55

3.1

13.9

1534

16.9

动物传播

动物传播

动物传播

动物传播

动物传播

动物传播

动物传播

动物传播

动物传播

动物传播

动物传播

动物传播

动物传播

动物传播

动物传播

动物传播

动物传播

动物传播

动物传播

动物传播

动物传播

自体传播

动物传播

动物传播 
郭志文, 郑景明. 用植物生活史性状预测种子扩散方式. 生物多样性, 2017, 25 (9)：966- 971. ht t p: //www. bi odi ver si ty- sci ence. net /CN/10. 17520/bi ods. 2017019

\begin{tabular}{|c|c|c|}
\hline 257 & 山茶科 Theaceae & 柃木属 Eurya \\
\hline 258 & 山茶科 Theaceae & 柃木属 Eurya \\
\hline 259 & 山茶科 Theaceae & 柃木属 Eurya \\
\hline 260 & 山茶科 Theaceae & 木荷属 Schima \\
\hline 261 & 山茶科 Theaceae & 山茶属 Camellia \\
\hline 262 & 山茶科 Theaceae & 山茶属 Camellia \\
\hline 263 & 山矾科 Symplocaceae & 山矾属 Symplocos \\
\hline 264 & 山矾科 Symplocaceae & 山矾属 Symplocos \\
\hline 265 & 山矾科 Symplocaceae & 山矾属 Symplocos \\
\hline 266 & 山矾科 Symplocaceae & 山矾属 Symplocos \\
\hline 267 & 山柑科 Capparaceae & 白花菜属 Cleome \\
\hline 268 & 山茱英科 Cornaceae & 灯台树属 Bothrocaryum \\
\hline 269 & 商陆科 Phytolaccaceae & 商陆属 Phytolacca \\
\hline 270 & 商陆科 Phytolaccaceae & 商陆属 Phytolacca \\
\hline 271 & 省沽油科 Staphyleaceae & 野鸦椿属 Euscaphis \\
\hline 272 & 十字花科 Cruciferae & 白芥属 Sinapis \\
\hline 273 & 十字花科 Cruciferae & 播娘蒿属 Descurainia \\
\hline 274 & 十字花科 Cruciferae & 大蒜芥属 Sisymbrium \\
\hline 275 & 十字花科 Cruciferae & 豆瓣菜属 Nasturtium \\
\hline 276 & 十字花科 Cruciferae & 独行菜属 Lepidium \\
\hline 277 & 十字花科 Cruciferae & 独行菜属 Lepidium \\
\hline 278 & 十字花科 Cruciferae & 独行菜属 Lepidium \\
\hline 279 & 十字花科 Cruciferae & 蔊菜属 Rorippa \\
\hline 280 & 十字花科 Cruciferae & 蔊菜属 Rorippa \\
\hline 281 & 十字花科 Cruciferae & 辣根属 Armoracia \\
\hline 282 & 十字花科 Cruciferae & 萝卜属 Raphanus \\
\hline 283 & 十字花科 Cruciferae & 荞属 Capsella \\
\hline 284 & 十字花科 Cruciferae & 菘蓝属 Isatis \\
\hline 285 & 十字花科 Cruciferae & 菘蓝属 Isatis \\
\hline 286 & 十字花科 Cruciferae & 碎米荠属 Cardamine \\
\hline 287 & 十字花科 Cruciferae & 糖芥属 Erysimum \\
\hline 288 & 十字花科 Cruciferae & 糖芥属 Erysimum \\
\hline 289 & 十字花科 Cruciferae & 糖芥属 Erysimum \\
\hline 290 & 十字花科 Cruciferae & 菥冥属 Thlaspi \\
\hline 291 & 十字花科 Cruciferae & 芸苔属 Brassica \\
\hline 292 & 十字花科 Cruciferae & 芸苔属 Brassica \\
\hline 293 & 十字花科 Cruciferae & 芸苔属 Brassica \\
\hline
\end{tabular}

格药柃 Eurya muricata 灌木

细齿叶柃 Eurya nitida 灌木

细枝柃 Eurya loquaiana乔木

木荷 Schima superba＼cjkstart乔木

茶 Camellia sinensis 灌木

山茶 Camellia japonica乔木

黄牛奶树 Symplocos laurina乔木

老鼠矢 Symplocos stellaris 灌木

山矾 Symplocos sumuntia 乔木

四川山矾 Symplocos setchuensis＼cjkstart草本

醉蝶花 Cleome spinosa 草本

灯台树 Bothrocaryum controversum 乔木

垂序商陆 Phytolacca americana 草本

商陆 Phytolacca acinosa 草本

野鸦椿 Euscaphis japonica 灌木

白芥 Sinapis alba 草本

播娘蒿 Descurainia sophia 草本

垂果大蒜芥 Sisymbrium heteromallum 草本

豆瓣菜 Nasturtium officinale 草本

独行菜 Lepidium apetalum 草本

宽叶独行菜 Lepidium latifolium 草本

密花独行菜 Lepidium densiflorum 草本

蔊菜 Rorippa indica 草木

沼生蔊菜 Rorippa islandica 草本

辣根 Armoracia rusticana 草本

萝卜Raphanus sativus 草本

荠 Capsella bursa-pastoris 草本

欧洲菘蓝 Isatis tinctoria var. tinctoria 草本

菘蓝 Isatis indigotica 草本

碎米荠 Cardamine hirsuta乔木

糖芥 Erysimum bungei 草本

糖芥（原变种） Erysimum bungei var. bungei

小花糖芥 Erysimum cheiranthoides 草本 菥营 Thlaspi arvense 草本

白菜 Brassica pekinensis 草本

青菜 Brassica chinensis 草本

芜菁 Brassica rapa 草本

\begin{tabular}{|c|c|c|c|}
\hline 6 & 肉质果 & 0.74 & 动物传播 \\
\hline 5 & 肉质果 & 1.25 & 动物传播 \\
\hline 10 & 肉质果 & 0.36 & 动物传播 \\
\hline 25 & 裂果 & 4.2 & 动物传播 \\
\hline 5 & 裂果 & 1405.2 & 自体传播 \\
\hline 9 & 裂果 & 775 & 自体传播 \\
\hline 10 & 肉质果 & 687.45 & 动物传播 \\
\hline 10 & 肉质果 & 27.24 & 动物传播 \\
\hline 15 & 肉质果 & 121.09 & 动物传播 \\
\hline 8 & 肉质果 & 67.23 & 自体传播 \\
\hline 1.5 & 裂果 & 1.71 & 自体传播 \\
\hline 15 & 肉质果 & 181.17 & 动物传播 \\
\hline 2 & 肉质果 & 7 & 动物传播 \\
\hline 1.5 & 肉质果 & 7 & 动物传播 \\
\hline 6 & 裂果 & 59.3 & 动物传播 \\
\hline 0.75 & 裂果 & 1.2 & 风传播 \\
\hline 0.7 & 裂果 & 0.1 & 自体传播 \\
\hline 0.9 & 裂果 & 0.28 & 自体传播 \\
\hline 0.3 & 裂果 & 0.19 & 自体传播 \\
\hline 0.3 & 裂果 & 0.23 & 自体传播 \\
\hline 1.5 & 裂果 & 0.19 & 自体传播 \\
\hline 0.3 & 裂果 & 0.4 & 自体传播 \\
\hline 0.4 & 裂果 & 0.7 & 自体传播 \\
\hline 0.8 & 裂果 & 0.06 & 自体传播 \\
\hline 1 & 裂果 & 0.59 & 自体传播 \\
\hline 1 & 裂果 & 18 & 动物传播 \\
\hline 0.5 & 裂果 & 3.8 & 自体传播 \\
\hline 1.2 & 裂果 & 10 & 自体传播 \\
\hline 1 & 裂果 & 2.21 & 风传播 \\
\hline 0.25 & 裂果 & 0.12 & 自体传播 \\
\hline 0.6 & 裂果 & 0.18 & 自体传播 \\
\hline 0.6 & 裂果 & 0.24 & 自体传播 \\
\hline 0.5 & 裂果 & 0.2 & 自体传播 \\
\hline 0.6 & 裂果 & 0.95 & 自体传播 \\
\hline 0.7 & 裂果 & 2.69 & 自体传播 \\
\hline 0.7 & 裂果 & 2.19 & 自体传播 \\
\hline 1 & 裂果 & 2.1 & 自体传播 \\
\hline
\end{tabular}


郭志文，郑景明．用植物生活史性状预测种子扩散方式. 生物多样性，2017，25 (9)：966-971. ht t p: //www. bi odi ver si ty- sci ence. net /CN/10. 17520/bi ods. 2017019

\begin{tabular}{|c|c|c|}
\hline 294 & 十字花科 Cruciferae & 芝麻菜属 Eruca \\
\hline 295 & 十字花科 Cruciferae & 诸葛菜属 Orychophragmus \\
\hline 296 & 石竹科 Caryophyllaceae & 我肠菜属 Myosoton \\
\hline 297 & 石竹科 Caryophyllaceae & 繁缕属 Stellaria \\
\hline 298 & 石竹科 Caryophyllaceae & 繁缕属 Stellaria \\
\hline 299 & 石竹科 Caryophyllaceae & 肥皇草属 Saponaria \\
\hline 300 & 石竹科 Caryophyllaceae & 狗筋蔓属 Cucubalus \\
\hline 301 & 石竹科 Caryophyllaceae & 孩儿参属 Pseudostellaria \\
\hline 302 & 石竹科 Caryophyllaceae & 卷耳属 Cerastium \\
\hline 303 & 石竹科 Caryophyllaceae & 麦仙翁属 Agrostemma \\
\hline 304 & 石竹科 Caryophyllaceae & 漆姑草属 Sagina \\
\hline 305 & 石竹科 Caryophyllaceae & 石竹属 Dianthus \\
\hline 306 & 石竹科 Caryophyllaceae & 石竹属 Dianthus \\
\hline 307 & 石竹科 Caryophyllaceae & 石竹属 Dianthus \\
\hline 308 & 石竹科 Caryophyllaceae & 蝇子草属 Silene \\
\hline 309 & 柿科 Ebenaceae & 柿属 Diospyros \\
\hline 310 & 柿科 Ebenaceae & 柿属 Diospyros \\
\hline 311 & 鼠李科 Rhamnaceae & 鼠李属 Rhamnus \\
\hline 312 & 鼠李科 Rhamnaceae & 枳椇属 Hovenia \\
\hline 313 & 檀香科 Santalaceae & 百芯草属 Thesium \\
\hline 314 & 卫矛科 Celastraceae & 卫矛属 Euonymus \\
\hline 315 & 五加科 Araliaceae & 刺楸属 Kalopanax \\
\hline 316 & 苋科 Amaranthaceae & 千日红属 Gomphrena \\
\hline 317 & 苋科 Amaranthaceae & 青葙属 Celosia \\
\hline 318 & 苋科 Amaranthaceae & 青葙属 Celosia \\
\hline 319 & 苋科 Amaranthaceae & 苋属 Amaranthus \\
\hline 320 & 苋科 Amaranthaceae & 苋属 Amaranthus \\
\hline 321 & 小檗科 Berberidaceae & 南天竹属 Nandina \\
\hline 322 & 小檗科 Berberidaceae & 十大功劳属 Mahonia \\
\hline 323 & 菖麻科 Urticaceae & 蝎子草属 Girardinia \\
\hline 324 & 菖麻科 Urticaceae & 菖麻属 Urtica \\
\hline 325 & 杨柳科 Salicaceae & 杨属 Populus \\
\hline 326 & 杨柳科 Salicaceae & 杨属 Populus \\
\hline 327 & 杨柳科 Salicaceae & 杨属 Populus \\
\hline 328 & 罂粟科 Papaveraceae & 蓟罂粟属 Argemone \\
\hline 329 & 罂粟科 Papaveraceae & 角茴香属 Hypecoum \\
\hline 330 & 罂粟科 Papaveraceae & 罂粟属 Papaver \\
\hline 331 & 罂粟科 Papaveraceae & 罂粟属 Papaver \\
\hline
\end{tabular}

芝麻菜 Eruca sativa

草本

诸葛菜 Orychophragmus violaceus 草本

鹅肠菜 Myosoton aquaticum 草本

繁缕 Stellaria media 草本

中国繁缕 Stellaria chinensis 草本

肥皇草 Saponaria officinaiis 乔木

狗筋蔓 Cucubalus baccifer 草本

孩儿参 Pseudostellaria heterophylla＼cjkstart草本

卷耳 Cerastium arvense 草本

麦仙翁 Agrostemma githago 草本

漆姑草 Sagina japonica草本

䝬麦 Dianthus superbus 草本

石竹 Dianthus chinensis 草本

香石竹 Dianthus caryophyllus 草本

麦瓶草 Silene conoidea 草本

野柿 Diospyros kaki 灌木

油柿 Diospyros oleifera乔木

薄叶鼠李 Rhamnus leptophylla灌木

枳椇 Hovenia acerba_乔木

百荵草 Thesium chinense 草本

扶芳藤 Euonymus fortunei

刺楸 Kalopanax septemlobus

千日红 Gomphrena globosa

鸡冠花 Celosia cristata

青葙 Celosia argentea

木质藤本

千穗谷 Amaranthus hypochondriacus 草本 0.8

尾穗苋 Amaranthus caudatus 草本 1.5

南天竹 Nandina domestica 灌木

十大功劳 Mahonia fortunei 灌木

蝎子草 Girardinia suborbiculata草本

宽叶菖麻 Urtica laetevirens 草本

黑杨 Populus nigra 乔木

苦杨 Populus laurifolia＼cjkstart乔木

密叶杨 Populus talassica乔木

蓟罂粟 Argemone mexicana 草本

角茴香 Hypecoum erectum 草本

罂粟 Papaver somniferum 草本

虞美人 Papaver rhoeas

0.9
0.5
0.8
0.3
1
0.7
1.5
0.2
0.35
0.9
0.2
0.6
0.5
0.7
0.6
14
14
5
25
0.4
1
30
0.6
0.8
1
0.8
1.5
3
2
1
1
30
15
16
1
0.6
0.3
0.9

\begin{tabular}{|c|c|c|}
\hline 裂果 & 1.98 & 自体传播 \\
\hline 裂果 & 2.5 & 自体传播 \\
\hline 裂果 & 0.26 & 自体传播 \\
\hline 裂果 & 0.3 & 风传播 \\
\hline 裂果 & 0.28 & 自体传播 \\
\hline 裂果 & 1.8 & 风传播 \\
\hline 裂果 & 1.42 & 动物传播 \\
\hline 裂果 & 3 & 风传播 \\
\hline 裂果 & 0.12 & 自体传播 \\
\hline 裂果 & 7 & 风传播 \\
\hline 裂果 & 0.02 & 自体传播 \\
\hline 裂果 & 0.64 & 自体传播 \\
\hline 裂果 & 1.9 & 风传播 \\
\hline 裂果 & 0.68 & 自体传播 \\
\hline 裂果 & 1.07 & 自体传播 \\
\hline 肉质果 & 384.61 & 动物传播 \\
\hline 肉质果 & 228.25 & 动物传播 \\
\hline 肉质果 & 13.17 & 动物传播 \\
\hline 肉质果 & 18.34 & 动物传播 \\
\hline 闭果 & 3.16 & 自体传播 \\
\hline 肉质果 & 25.14 & 动物传播 \\
\hline 肉质果 & 6.57 & 动物传播 \\
\hline 裂果 & 0.9 & 风传播 \\
\hline 裂果 & 0.8 & 风传播 \\
\hline 裂果 & 0.8 & 风传播 \\
\hline 闭果 & 0.7 & 自体传播 \\
\hline 裂果 & 0.5 & 风传播 \\
\hline 肉质果 & 19.2 & 动物传播 \\
\hline 肉质果 & 19 & 动物传播 \\
\hline 闭果 & 2.14 & 自体传播 \\
\hline 闭果 & 0.39 & 自体传播 \\
\hline 裂果 & 0.81 & 风传播 \\
\hline 裂果 & 0.83 & 风传播 \\
\hline 裂果 & 0.81 & 风传播 \\
\hline 裂果 & 2.2 & 风传播 \\
\hline 裂果 & 0.24 & 自体传播 \\
\hline 裂果 & 0.3 & 风传播 \\
\hline 裂果 & 0.33 & 风传播 \\
\hline
\end{tabular}


郭志文，郑景明．用植物生活史性状预测种子扩散方式．生物多样性，2017，25 (9)：966-971. ht t p: //www. bi odi ver si ty- sci ence. net /CN/10. 17520/bi ods. 2017019

\begin{tabular}{|c|c|c|}
\hline 332 & 榆科 Ulmaceae & 糙叶树属 Aphananthe \\
\hline 333 & 榆科 Ulmaceae & 朴属 Celtis \\
\hline 334 & 榆科 Ulmaceae & 榆属 Ulmus \\
\hline 35 & 樟科 Lauraceae & 木姜子属 Litsea \\
\hline 36 & 樟科 Lauraceae & 木姜子属 Litsea \\
\hline 37 & 樟科 Lauraceae & 楠属 Phoebe \\
\hline 38 & 樟科 Lauraceae & 润楠属 Machilus \\
\hline 339 & 樟科 Lauraceae & 山胡椒属 Lindera \\
\hline 40 & 樟科 Lauraceae & 山胡椒属 Lindera \\
\hline 41 & 樟科 Lauraceae & 新木姜子属 Neolitsea \\
\hline 342 & 樟科 Lauraceae & 樟属 Cinnamomum \\
\hline 43 & 樟科 Lauraceae & 樟属 Cinnamomum \\
\hline 44 & 樟科 Lauraceae & 樟属 Cinnamomum \\
\hline 34 & 樟科 Lauraceae & 樟属 Cinnamomum \\
\hline 346 & 紫金牛科 Myrsinaceae & 紫金牛属 Ardisia \\
\hline 347 & 紫金牛科 Myrsinaceae & 紫金牛属 Ardisia \\
\hline 348 & 紫金牛科 Myrsinaceae & 紫金牛属 Ardisia \\
\hline 349 & 紫金牛科 Myrsinaceae & 紫金牛属 Ardisia \\
\hline 350 & 紫金牛科 Myrsinaceae & 紫金牛属 Ardisia \\
\hline 51 & 紫金牛科 Myrsinaceae & 紫金牛属 Ardisia \\
\hline & 紫金牛科 Myrsinaceae & 紫金牛属 Ardisia \\
\hline 353 & 紫金牛科 Myrsinaceae & 紫金牛属 Ardisia \\
\hline & 紫茉莉科 Nyctaginaceae & 紫茉莉属 Mirabilis \\
\hline 25 & 紫葳科 Bignoniaceae & 菜豆树属 Radermachera \\
\hline & 科 Bignoniaceae & 角蒿属 Incarvillea \\
\hline & 科 Bignoniaceae & 猫尾木属 Dolichandrone \\
\hline & 斗 Bignoniaceae & 楸属 Stereospermum \\
\hline & 科 Bignoniaceae & 楸属 Stereospermum \\
\hline & 科 Oxalidaceae & 属 Oxalis \\
\hline
\end{tabular}

朴树 Celtis sinensis 乔木

榆树 Ulmus pumila 乔木

木姜子 Litsea pungens 乔木

清香木姜子 Litsea euosma 乔木

楠木 Phoebe zhennan＼cjkstart乔木

润楠 Machilus pingii 乔木

川钓樟 Lindera pulcherrima＼cjkstart乔木

香叶树 Lindera communis 灌木

浙江新木姜子 Neolitsea aurata var.

chekiangensis

肉桂 Cinnamomum cassia 乔木

香桂 Cinnamomum subavenium 乔木

油樟 Cinnamomum longepaniculatum 乔木

樟 Cinnamomum camphora乔木

滇紫金牛 Ardisia yunnanensis＼cjkstart乔木

多枝紫金牛 Ardisia sieboldii 灌木

罗伞树 Ardisia quinquegona var.

quinquegona

纽子果 Ardisia virens

伞形紫金牛 Ardisia corymbifera

尾叶紫金牛 Ardisia caudata

圆果罗伞 Ardisia depressa

紫金牛 Ardisia japonica

紫茉莉 Mirabilis jalapa

豇豆树 Radermachera pentandra

高波罗花 Incarvillea altissima

西南猫尾木 Dolichandrone stipulata

毛叶羽叶楸 Stereospermum

羽叶楸 Stereospermum colais

白花酢浆草 Oxalis acetosella

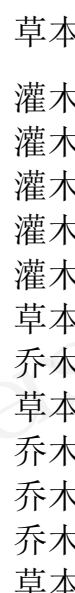

\begin{tabular}{lll} 
肉质果 & 237.85 & 动物传播 \\
闭果 & 43 & 动物传播 \\
闭果 & 4 & 风传播 \\
肉质果 & 26.78 & 动物传播 \\
肉质果 & 80.42 & 动物传播 \\
肉质果 & 1450 & 动物传播 \\
肉质果 & 3333 & 动物传播 \\
肉质果 & 275.6 & 动物传播 \\
肉质果 & 78.56 & 动物传播 \\
肉质果 & 437.2 & 动物传播 \\
肉质果 & 209 & 动物传播 \\
肉质果 & 106 & 动物传播 \\
肉质果 & 262 & 动物传播 \\
肉质果 & 116 & 动物传播 \\
肉质果 & 126.27 & 动物传播 \\
肉质果 & 99.67 & 动物传播 \\
肉质果 & 43.49 & 自体传播 \\
肉质果 & 96.58 & 动物传播 \\
肉质果 & 101.23 & 动物传播 \\
肉质果 & 60.39 & 动物传播 \\
肉质果 & 84.4 & 动物传播 \\
肉质果 & 86.23 & 动物传播 \\
闭果 & 93.3 & 动物传播 \\
裂果 & 12.74 & 风传播 \\
裂果 & 3.29 & 风传播 \\
裂果 & 68.73 & 风传播 \\
裂果 & 10.8 & 风传播 \\
裂果 & 15.8 & 风传播 \\
裂果 & 1.15 & 自体传播 \\
& & \\
\hline
\end{tabular}

